\title{
Effectiveness of Structured Teaching Programme on Knowledge of Staff Nurses Regarding Coronary Angiogram at a Selected Hospital, Bangalore
}

\author{
Preethi George ${ }^{1}$, Umadevi A $\mathbf{K}^{2}$ \\ ${ }^{1} \mathrm{MSc}(\mathrm{N})$ Student, ${ }^{2}$ Associate Professor, \\ Dept. of MSN, Kempegowda College of Nursing, Bangalore, India \\ Corresponding Author: Umadevi A K
}

\begin{abstract}
The aim of the study was to assess the effectiveness of Structured Teaching Programme (STP) on knowledge of staff nurses regarding coronary angiogram. The study involved one group pre-test and post-test using pre-experimental design, with non-probability sampling technique in which purposive sampling method was used. Sixty staff nurses working at Kempegowda Institute of Health Science and Research Center were taken as samples $(n=60)$ and requested to mark the structured knowledge questionnaire followed by implementation of STP on the same day and post-test conducted on the 15th day, using the same structured knowledge questionnaire to find out the effectiveness. The results revealed that in posttest there was a significant gain in knowledge of staff nurses with a mean of $23.83+2.21$ compared to pretest mean of $17.90+$ 2.79 and the improvement was statistically significant $(p<0.05)$. There was no significant association found in relation to any of the demographic variables. The overall findings of the study clearly showed that the STP was significantly effective in improving the knowledge of staff nurses regarding coronary angiogram.
\end{abstract}

Keywords: Effectiveness, structured teaching programme, coronary angiogram, staff nurses, knowledge and structured knowledge questionnaire.

\section{INTRODUCTION}

The heart is one of the most important organs in the human body. It is a hollow muscular organ that pumps blood throughout the blood vessels by repeated, rhythmic contractions. However, there are conditions and diseases that affect the heart and its functions. ${ }^{1}$ The diagnostic tests in cardiology are methods of identifying heart conditions associated with healthy Vs unhealthy, pathologic heart function ${ }^{3}$.

According to Rath, among many health predictions in the millennium, the most alarming conditions are heart disease and stroke. But coronary Artery Disease is becoming one of the leading causes for morbidity and mortality in developed countries. The prominent public health problem is emerging now in developing countries like India. The alarming growth of heart disease in India is estimated approximately 10 million people by $2010^{8}$.

The last few decades have seen an advancement of research in the methods of diagnosing, treating and controlling the coronary artery disease. In 1929 Werner Forssmann exposed a vein in his left arm and introduced a ureteric catheter and advanced it under the fluoroscope and placed in to the right atrium. Credits must be given to Cournand and Ranges (1941) and Richard (1945) who carried out a series of original investigations into right side of the heart and pulmonary artery in human heart. Further development of various cardiac and coronary procedures came rapidly. In 1959 selective coronary arteriography was reported as an excellent 
technique and it was modified into percutaneous approach by Rickets and Abram in $1962 \& 1967^{9}$.

World Health Organization (WHO) has reported that, "approximately 50 million deaths occur throughout the world every year, with almost $80 \%$ of these (40 million) occurs in developing countries due to cardiovascular disease". It has been estimated that approximately one quarter of all deaths in developing countries and worldwide half of all deaths are due to cardiovascular diseases. Among cardiovascular diseases Coronary Artery Disease (CAD) is the leading disease causing high mortality and morbidity. WHO report stated that coronary disease accounted for more than 8 million deaths worldwide. In industrialized countries CAD is responsible for $1 / 3^{\text {rd }}$ of total deaths ${ }^{10}$.

The tremendous advancements made in medical technology demands for specialized nursing technology in coronary care. The success of this specialization is depending on the competencies of the nursing personnel on the early diagnosis and to 4 provides need based care to promote optimum health in cardiac catheterization. In order to function effectively, the nurses have to strengthen and modify their functional ability through continuous assessment of knowledge and practice ${ }^{15}$.

A descriptive study was conducted in Israel to assess the appropriateness of performing coronary angiography in two major teaching hospitals among 499 patients who underwent coronary angiography. The result revealed that angiographies were performed inappropriately in 58\% of patients. The investigator concluded that in most of the cases inappropriate coronary angiography are due to error in management before performing angiographies. The study concluded that there is a need for further teaching regarding coronary angiogram ${ }^{16}$.

A study was conducted in USA on The Need for Improvement and the Barriers to Adoption of New Technology in coronary angiography .The traditional coronary angiography presents a variety of limitations related to image acquisition, content, interpretation, and patient safety. Barriers for improvements include, the paucity of clinical outcomes, studies related to new imaging technology, the resistance to changing long-standing practices. The study suggests that there is a need for physician and staff member training regarding coronary angiogram ${ }^{18}$.

The review of literature shows that there is a need for staff member training regarding coronary angiogram. Hence the investigator felt the need for improving knowledge of nurses regarding coronary angiogram. This study will highlight the involvement of nurses in care of patients with coronary angiogram. Further this study will help the nursing professionals in gaining an insight regarding coronary angiogram. With this intention the present study attempts to assess the "Effectiveness of structured teaching programme on knowledge of staff nurses regarding coronary angiogram at a selected hospital, Bangalore".

\section{METHODS AND MATERIALS}

Research approach and research design: For the present study quantitative research approach and pre experimental one group pre-test post-test research design were used to accomplish the stated objectives.

Attribute variable: Age and work experience.

Independent variable: Structured teaching programme on coronary angiogram.

Dependent variable: Knowledge of staff nurses regarding coronary angiogram.

Research setting: Kempegowda Institute of Medical Sciences Hospital and Research Centre, Bangalore, India

Sample and sampling technique: The investigator selected a sample of 60 registered staff nurses using a purposive sampling technique. 
Inclusion criteria: Staff nurses who were willing to participate in the study and present at the time of data collection.

Exclusion criteria: Staff nurses who are already exposed to the education programme on coronary angiogram.

Ethical consideration: Institutions Human Ethics committee clearance and permission was obtained from Kempegowda Institute of Medical Science Hospital and Research Center, Bangalore. All the staff nurses involved in the study were informed that the participation will be on voluntary basis and they can withdraw from the study at any time. Prior written informed consent was taken from all the participants.

Description of tool: The tool consisted of following two parts:

Part I Consists of Socio demographic characteristics such as age, sex, professional qualification, marital status, religion, family, monthly family income, and total years of experience.

Part II Consists of 40 items pertaining to knowledge regarding coronary angiogram. It is divided into 5 aspects such as:

$>$ Anatomy and physiology of heart

$>$ History, statistics and definition of coronary angiogram

$>$ Indications and contraindications of coronary angiogram

$>$ Complications of coronary angiogram

$>$ Procedure of coronary angiogram

\section{Scoring Interpretation}

Each correct answer was given a score of one and for wrong answer a score of zero. To find out the knowledge scores, the respondents were categorized into three groups.

Adequate knowledge-score of 31and above (75\%-100\%)

Moderate Knowledge-score between 21-30 (51\%-74\%)

Inadequate Knowledge-score below 20 (Below 50\%)

Maximum Score $=40$, Minimum Score $=$ o (Zero)
Reliability of tool: Split Half method with Spearman's Brown Prophecy formula was used to test the reliability of the tool $(\mathrm{r}=0.82)$.

\section{Development of the Structured Teaching Programme}

Structured Teaching Programme (STP) on knowledge of staff nurses regarding coronary angiogram was developed based on literature review, consulting with experts and research guide. The steps adopted in the development of STP were:

- Preparation of first draft of STP content.

- Development of criteria checklist to evaluate the STP Content.

- Content validity of STP.

- Preparation of final draft of STP.

\section{Description of the Intervention}

\section{Pulmonary Rehabilitation Services Include}

- Respiratory muscle retraining

- Nutritional counselling

- Guidelines for cessation of smoking

- Stress relaxation \& energy conservation techniques

\section{Data collection procedure}

Formal permission was obtained from Administrative Medical Officer and Nursing Director of Kempegowda Institute of Medical Science Hospital and Research Center to conduct the study through the Principal, Kempegowda College of Nursing. The data collection was carried out in Kempegowda Institute of Medical Science Hospital and Research Center, Bangalore from $10 / 10 / 2013$ to $10 / 12 / 2013$.

The need for the study and the objectives were explained to the staff nurses. Anonymity and confidentiality was assured and written informed consent was obtained from the participants before conducting the pretest. The investigator collected data from 60 nurses that took 4045 minutes for each nurse to complete the structured knowledge questionnaire.

After pre-test, the STP was conducted for 60 samples for about 45 
minutes by using power point. All the staff nurses cooperated well and participated actively. They came forward with their queries about coronary angiogram and they were satisfied with the answers they received. They also showed a positive attitude in group discussion.

Posttest data was conducted on 8th day after STP by using the same selfadministered knowledge questionnaires on coronary angiogram. All the participants were cooperated well with the investigator in both pretest and posttest sessions. The data collection process was terminated by thanking the subjects for their cooperation.

\section{Statistical analysis}

Statistics were performed by using SPSS-IBM 20. Results were calculated by using $\mathrm{P}$ value $<0.05$. Chi-square was used to associate the level of knowledge with selected demographic variables. Frequency and percentage distribution was used to analyze the demographic variables.

\section{Description of demographic \\ characteristics}

\section{Assessment of knowledge of staff nurses regarding coronary angiogram. Objective: to assess the knowledge of staff nurses regarding coronary angiogram.}

Table 1: Distribution of Aspect wise and overall scores of respondents in Pretest and Post test $N=60$

\begin{tabular}{|c|l|c|c|c|c|}
\hline \multicolumn{1}{|c|}{ Table 1: Distribution of Aspect wise and overall scores of respondents in Pretest and Post test } & \multicolumn{3}{|c|}{ Pre-test } & \multicolumn{2}{|c|}{ Post-test } \\
\hline
\end{tabular}

* Significant at $\mathrm{p}<0.05$ NS - Non Significant

Table 1 depicts the overall and aspect wise knowledge scores of respondent on coronary angiogram in pretest and posttest. The mean overall posttest mean knowledge score was 23.83 compared to pretest mean score of 17.90 with the knowledge enhancement of $76.7 \%$. Paired ' $\mathrm{t}$ ' test was used to assess the significance difference between pre and posttests (23.707) and this was statically significant $(\mathrm{p}<0.05)$. This result indicated that the improvement of knowledge among staff nurses was only because of STP.

The study findings are supported by a study conducted to assess the knowledge of nurses towards coronary angiogram in a Tertiary care Teaching Hospital in Nepal. The result revealed that the mean $\pm \mathrm{SD}$ age of the respondents was $22.07 \pm 2.30$ years and their mean \pm SD duration of experience was $11.45 \pm 2.67$ months $^{17}$.

The findings are also supported by a similar study conducted To assess the effect 
of an educational intervention on nurses knowledge and management of PCI procedures in China. The study concluded that there was a substantial and statistically significant improvement of knowledge after a lecture based workshop, mean $=8.2$, $\mathrm{SD}=1.1$ and mean=15.5, $\mathrm{SD}=1.3$ on 18 items, before and after teaching respectively, $\mathrm{p}<0.001^{33}$.

\section{Association between Demographic variables and Pretest Knowledge level on Coronary Angiogram \\ Objective: to find out the association between pre-test knowledge scores of staff nurses with selected demographic variables.}

Table 2: Association between Demographic variables and Pretest Knowledge level on Coronary Angiogram N=60

\begin{tabular}{|c|c|c|c|c|c|c|c|}
\hline Demographic variables & Responses & \multicolumn{2}{|c|}{ Overall pretest knowledge } & $\begin{array}{c}\text { Chi- square } \\
\text { value }\end{array}$ & Df & P-value & Inference \\
\hline Age in Years & More than 25 & 21 & 17 & 0.155 & 1 & 3.84 & NS \\
\hline Professional qualification & PBBSc & - & 1 & 0.20 & 1 & 3.84 & NS \\
\hline \multirow[t]{2}{*}{ Years of clinical experience } & Less than 10 & 26 & 18 & \multirow[t]{2}{*}{1.116} & \multirow[t]{2}{*}{1} & \multirow[t]{2}{*}{3.84} & \multirow[t]{2}{*}{ NS } \\
\hline & More than 10 & 7 & 9 & & & & \\
\hline \multirow{2}{*}{ Marital status } & Married & 20 & 17 & \multirow{2}{*}{0.678} & \multirow{2}{*}{2} & \multirow{2}{*}{5.99} & \multirow{2}{*}{ NS } \\
\hline & Others & 1 & 2 & & & & \\
\hline \multirow[t]{2}{*}{ Religion } & Hindu & 8 & 3 & \multirow[t]{2}{*}{1.415} & \multirow[t]{2}{*}{1} & \multirow[t]{2}{*}{3.84} & \multirow[t]{2}{*}{ NS } \\
\hline & Christian & 26 & 23 & & & & \\
\hline \multirow[t]{2}{*}{ Monthly family income } & Less than 10000 & 7 & 6 & \multirow[t]{2}{*}{0.054} & \multirow[t]{2}{*}{1} & \multirow[t]{2}{*}{3.84} & NS \\
\hline & More than 10000 & 27 & 20 & & & & \\
\hline
\end{tabular}

Table 2 shows the association association between pre-test knowledge scores of staff nurses with selected demographic variables. Chi-Square was used to find out the association between the variables $\mathrm{x}^{2}$ and $\mathrm{p}$ value indicated that there was no association found in the variables such as age, professional qualification, years of clinical experience, marital status, religion, monthly family income and type of family $(\mathrm{p}<0.00)$.

The study findings are similar to the study conducted to assess the knowledge of nurses towards coronary angiogram in a Tertiary care Teaching Hospital in Nepal. The study result revealed that there was no significant association between the total scores and age $(\mathrm{p}=0.823)$ and the duration of experience $(\mathrm{p}=0.239)^{17}$.

\section{Limitations}

$>$ The present study was limited to staff nurses working at Kempegowda Institute of Medical Science Hospital and Research Centre, Bangalore.
$>$ Only single domain knowledge was considered in the present study.

$>$ The study did not used any control group and randomization.

$>$ The sample for this study was limited to 60 staff nurses only.

\section{CONCLUSION}

Nurses as competent professionals have responsibility to promote health information and practice among health professionals in the hospitals. Today health care delivery system mainly focus on primary prevention and health education that can be achieved through health education, that brings improvement in knowledge, attitude and practice of nurses working in the various areas like medical ward, surgical ward, pediatric ward, casualty, ICU etc. Nurses should be encouraged to attend continuing education programme through planned teaching, incidental teaching. There is a need to increase knowledge and skill regarding coronary angiogram. 
The findings of this study may be utilized as a basis for in-service education of nurses, so that a constant and clear understanding may be created regarding coronary angiogram.

Acknowledgement: We thank all the volunteers engaged in this study protocol. The authors wish to acknowledge everyone who has offered their support throughout this endeavor. Thank you to family and friends who were always there whenever they were needed and whose encouragement and sacrifice has greatly contributed to this work.

Disclosure: None of the above listed authors has competing interests to declare regarding the publication of this article.

\section{Sources of support: Nil}

\section{Ethical Approval: Approved}

\section{REFERENCES}

1. Kuklina E, Yoon PW, Keenan NL. Prevalence of coronary heart disease risk factors and screening for high cholesterol levels among young adults, United States, 1999-2006. Ann Fam Med. Jul-Aug 2010;8(4):327-33. doi: 10.1370/afm.1137.

2. Richard LM, Timothy AS. The history of interventional Cardiology: Cardiac catheterization, angioplasty and related interventions. American Heart Journal.1995 January; 129(1):146-72.

3. Joseph P. Coronary Angiogram. Live strong.com.2010 June 14; 10(2):18-20.

4. Ward G, Leachman V, Fihali S. Cost of Cardiac surgery in India. Chest Journal. 1985 September; 88(3).

5. Woods LS. Cardiac nursing.3rd ed. Philadelphia: JB Lippincott Company; 1995. P 439-447.

6. Rath PC. Emergency trends in treatment of cardiac problems. Times News Network.2004 Jan2; 26 (2):17-20.

7. Grifka RG. Tran catheter intervention for the treatment of congenital cardiac defects. Texas Heart Institute Journal.1997; 24(4): 293-300.

8. WHO task force on the development of module banks. Self learning material and modules for Health worker, a guide for their development utilization and evaluation. New Delhi.1983; 5-14.

9. Elizebeth E. Cardiac catheterization Technique and Teaching. Nursing clinics of North America.2004;11(2):271-281.

10. Bowden T. Evidence based care for patients undergoing coronary angiography. British Journal of Nursing.2009 July9; 18(13):77883.75

11. Brunner LS. Text book of medical surgical nursing. Philadelphia: Lippincott company; 1998.p (356-368).

12. Jame LR, Raymond J. ACC/AHA Guidelines for Coronary Angiography: Executive Summary\& Recommandations. ACC/AHA practice guidelines.1999 May 4.

13. Oliver MF, Newton MK. Modern trends in cardiology.3rd ed. London: Butterworth \&Company; 1996.

14. Mozes B. The appropriateness of performing coronary angiography in 2 major teaching hospitals in Israel. International Journal for Quality in Health care.1994 April;6(3):245-49.

15. David C. Knowledge of nurses towards coronary angiogram in a tertiary care teaching hospital in Nepal.1999 July 14; 28292).

16. Caroll JD. Chen SJ. Coronary Angiography: the need for improvement and the barriers to adoption of new technology.2009 Aug; 27(3): 373-83.

17. Leibowitz AB, Silverstein JH. Assessment of critical care nurses knowledge of the pulmonary artery catheter. The pulmonary artery catheter study group. Critical Care Med.1994 Oct; 22(10):1674-8.

18. Burn N, Grove K. Understanding Nursing Research.2nd ed. Philadelphia: WB Saunders Company; 1998.p 293-301.

19. Polit DF, Hungler BP. Nursing Research, principles and methods.6th ed. Philadelphia: Lippincott Company: 2005. P 117-25, 26, 28.

20. Rolley JX, Cheryl R. Nursing Care practices following a percutaneous coronary intervention: Results of a survey of Australian and New Zealand Cardiovascular nursing.2010 Feb; 25(1):75-84.

21. Jose AB, Agustin A. Spanish Cardiac catheterization and coronary intervention registry. 18th official report of the Spanish society of cardiology working group on cardiac catheterization and interventional 
Preethi George et.al. Effectiveness of structured teaching programme on knowledge of staff nurses regarding coronary angiogram at a selected hospital, Bangalore

cardiology. Rev Esp Cardiol.2009; 62912): 1418-34.

22. Vtankulu MA, Kayrak M. A rare but serious complication of PCI: Spinal cord embolism. J Spinal Cord Med.2010; 33(1): 85-9.

23. West R, Ellis G. Complications of diagnostic cardiac catheterization; results from a confidential inquiry into cardiac catheter complications. Heart. 2005 June; 92(6):810-12

24. Andersen K, Kaestel H. Haematoma after coronary angiography and percutaneous coronary intervention via the femoral artery frequency and risk factors. Journal of cardiovascular nursing. 2005 Jun; 4(2): 1237.

25. Dangas G, Mehran R, Salter LF. Vascular complications after percutaneous coronary interventions following hemostasis with manual compression versus arteriotomy closure devices.JAM Coll Cardiol.2001 Sep; 38(3): 638-41.

26. Hinteze G, Fink H. Risk of iodine induced thyrotoxicosis after coronary angiography: an investigation in 788 unselected subjects. Eur J. Endocrinol.1999 Mar; 140(3): 264-7.

27. Walker S, Jen C.Comparison of complications in percutaneous coronary intervention patients mobilized at 3, 4 and 6 hours after femoral arterial sheath removal.
J Cardiovasc.Nurs.2008 Sep-Oct; 23(5): 407-13

28. Chair SY,Lam G,Chan S. Effect of positioning on back pain after coronary angiography. J Adv Nurs. 2003 Jun; 42(5): 470-8.

29. Sola R, Pastore GM. Early ambulation after diagnostic cardiac catheterization: a 4 French study. J Invasive Cardiol.2001 Feb; 13(2): 75-8.

30. Mari B, Betty W, Kate S. The effect of pressure bandaging on complications and comfort in patients undergoing coronary angiography: A multicenter randomized trial. Heart \& Lung: The journal of acute and critical care.1998 Nov; 27(6): 360-73.

31. Robert B. Management of PCI: The efficacy of an educational intervention on nurses knowledge. Academic Journal.2012; 6(4): 1190.

How to cite this article: George P, Umadevi A K. Effectiveness of structured teaching programme on knowledge of staff nurses regarding coronary angiogram at a selected hospital, Bangalore. International Journal of Science \& Healthcare Research. 2021; 6(3): 431-437. DOI: https://doi.org/10.52403/ijshr. 20210770 